J. Lake Sci. ( 湖泊科学 ), $2006, \mathbf{1 8}(1): 36-42$

http:// www. jlakes. org. E-mail: jlakes@ niglas. ac.cn

(c) 2006 by Journal of Lake Sciences

\title{
长江中下游湖泊沉积物生物可利用磷分布特征"
}

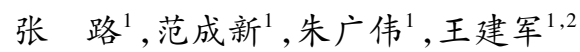 \\ ( 1 : 中国科学院南京地理与湖泊研究所,南京 210008 ) \\ ( 2: 中国科学院研究生院, 北京 100039 )
}

摘 要: 利用化学提取方法对太湖 6 个样点, 巢湖 4 个样点和龙感湖 3 个样点的表层沉积物和沉积物柱样进行了生物可 利用磷( BAP) 测定. 北太湖表层沉积物的平均含量为 $259.5 \mathrm{mg} / \mathrm{kg}$, 而西部湖区平均含量为 $114.6 \mathrm{mg} / \mathrm{kg}$, 湖心区平均含量 为 $40.6 \mathrm{mg} / \mathrm{kg}$, 而东太湖平均含量为 $50.7 \mathrm{mg} / \mathrm{kg}$, 呈显著北高南低的特点. 巢湖西部湖区表层沉积物的 BAP 平均含量为 $254.2 \mathrm{mg} / \mathrm{kg}$, 而东部湖区 BAP 含量降低为 $101.9 \mathrm{mg} / \mathrm{kg}$. 龙感湖表层沉积物 BAP 平均含量为 $67.8 \mathrm{mg} / \mathrm{kg}$. 显著表明污染 程度较高的湖区沉积物的 BAP 相应较高. BAP 在沉积物中随深度呈指数降低,显示生物可利用磷在沉积作用下向稳定的 非活性磷转化. 夏季沉积物中的 BAP 由于生物活性的增强向溶解态活性磷转化过程增强, 显示为较低的 BAP 含量. BAP 含量与水体溶解态活性磷呈正相关关系, 且该相关性在 BAP 含量较低的样点好于高 BAP 的样点.

关键词: 沉积物; 生物可利用磷;太湖; 巢湖; 龙感湖

\section{Distribution of Bioavailable Phosphorus ( BAP ) in lake sediments of the middle and lower reaches of the Yangtze River}

\author{
ZHANG Lu ${ }^{1}$, FAN Chengxin ${ }^{1}$, ZHU Guangwei ${ }^{1} \&$ WANG Jianjun ${ }^{1,2}$ \\ ( Nanjing Institute of Geography and Limnology, CAS, Nanjing, 210008, PR. China ) \\ ( Graduate School of Chinese Academy of Sciences, Beijing 100039,PR. China)
}

\begin{abstract}
Bioavailable Phosphorus ( BAP) in sediments of Lake Taihu ( 6 sites ), Lake Chaohu ( 4 sites ) and Lake Longgan ( 3 sites ) was analyzed by chemical extraction method. The mean BAP content in north Lake Taihu was $259.5 \mathrm{mg} / \mathrm{kg}, 114.6 \mathrm{mg} / \mathrm{kg}$ in west of Lake Taihu, $40.6 \mathrm{mg} / \mathrm{kg}$ in the middle of the lake and $50.7 \mathrm{mg} / \mathrm{kg}$ in East Lake Taihu. It was very obvious that BAP contents were higher in the north of the lake and lower in the south. The mean BAP content in the west of Lake Chaohu was $254.2 \mathrm{mg} / \mathrm{kg}$ while was $101.9 \mathrm{mg} / \mathrm{kg}$ in the east of the lake. The content is $67.8 \mathrm{mg} / \mathrm{kg}$ in Lake Longgan. All these data showed the more polluted lakes ( lake zones ) was with higher BAP contents in the sediments. The BAP contents in the sediment cores decreased exponentially that meant the BAP would transform to non-bioavailable form with sedimentation effect. Because of the higher bioactivity in summer, the BAP was more easily transformed to soluble phosphorus and resulted in lower content in the sediment. There was positive correlation between the BAP contents in sediments and soluble reactive phosphorus ( SRP ) and the correlation was better in the lakes/lake zones with lower BAP contents than in the lakes/lake zones with higher contents.
\end{abstract}

Keywords: Sediment, Bioavailable Phosphorus ( BAP ); Lake Taihu; Lake Chaohu; Lake Longgan

磷的生物可利用性一直是国内外专家学者关注的热点 ${ }^{[1-5]}$. 一般认为, 藻类和其他浮游生物在利用磷 作为生长繁殖的营养时, 溶解性活性磷酸盐( SRP )往往首先被利用. 在 SRP 不够使用或其浓度低到一定程 度时, 生物会通过水解、酶解等生物化学反应, 转而利用其他形态的磷. 可以认为持续提供藻类生长可利用

* 国家自然科学基金( 20577053,40501064), 国家“十五”重大科技专项( 863 )项目( 编号: 2002AA601013), 中国科学 院知识创新工程重大项目( KZCX1 - SW - 12)联合资助. 2005-04-19 收稿;2005-08-30 收修改稿. 张路, 男, 1975 年生, 博士,助理研究员; E-mail: luzhang1975@ hotmail. com;luzhang@ niglas. ac. cn. 
的磷往往更多来自于潜在活性的磷 ${ }^{[1]}$. Mortimer ${ }^{[6]}$ 认为铁锰氧化物结合态磷以及部分有机磷是内源负荷的 重要来源.

生物可利用磷( Bioavailable Phosphorus, BAP )含量的测定方法一般有三类:( 1 )“藻类标准培养程序” ( Standardized algal assay procedure $)^{[5,7]}$. 该方法通过藻类培养生长曲线直接估算沉积物中可被藻类降解利 用的总磷量, 称为藻类可利用磷 (Algae Available Phosphorus, AAP). 经典的藻类培养程序需要 100 天 $^{[8]}$. ( 2 )直接采用化学提取剂提取. 由于直接提取法与藻类标准培养程序测定得到的可利用磷有很好的相关关 系, 能够反映藻类等生物的潜在可利用的量, 且操作非常简便, 能够适应大量样品的快速测定要求 ${ }^{[4,5,9]}$. 该 方法得到的生物可利用磷相当于沉积磷的连续提取方法中得到的活性磷、铁锰结合态磷、铝结合态磷和部 分有机磷的总和. (3) 铁氧化物试纸法( Iron-impregnated paper strip ). 这种方法首先运用于雨水、径流或者 河流水体中生物可利用磷的测定 ${ }^{[10,11]}$. 对于沉积物样品的测定仍有争议. 由于该方法提取效率取决于水 体及悬浮物中可提取磷的总量,必须保证可提取磷不超过试纸的饱和容量才有较高的准确度.

长江中下游湖泊普遍遭受着富营养化的环境演化,而沉积物内源性的磷负荷显然对富营养化进程有重 要的作用. 虽然沉积物藻类可利用磷的含量有别于湖泊内源负荷 ${ }^{[2]}$, 但正确评估沉积物中藻类可利用磷 的总量, 对于了解湖泊沉积物内源负荷的影响及对湖泊富营养化的贡献仍是至关重要的. 本文以不同生态 类型及不同污染程度的太湖, 龙感湖和巢湖为研究对象, 分别代表草藻型混合湖泊, 草型湖泊和藻型湖泊进 行表层沉积物和沉积物柱样的生物可利用磷空间差异及季节性变化研究,并将生物可利用磷含量和水体的 营养状态初步建立联系.

\section{1 样点布设与采集}

图 1 显示太湖、龙感湖及巢湖的沉积物采样点. 其中,太湖的 6 个样点分别为: $\mathrm{T} 1$ 为梁溪河口, $\mathrm{T} 2$ 为梅 梁湾, T3 为竺山湖, T4 为湖心区, T5 为大浦口, T6 为草型湖区东太湖. 巢湖的 4 个样点中 $\mathrm{C} 1$ 为主要污染物 人湖区, 从 C1 到 C4 表现为上游到下游污染物逐步稀释的过程. 龙感湖三个样点分别为 L1, L2 和 L3. 采样 在 2002 年 10 月、2003 年 1 月及 2003 年 7 月分三次进行,分别代表秋冬夏三季. 利用无扰动柱样采集器现 场采集沉积物样品. 表层沉积物指沉积物柱样 $0-2 \mathrm{~cm}$ 深度的样品, 同时采集沉积物上覆水分析溶解态活 性磷酸盐( SRP) 含量.

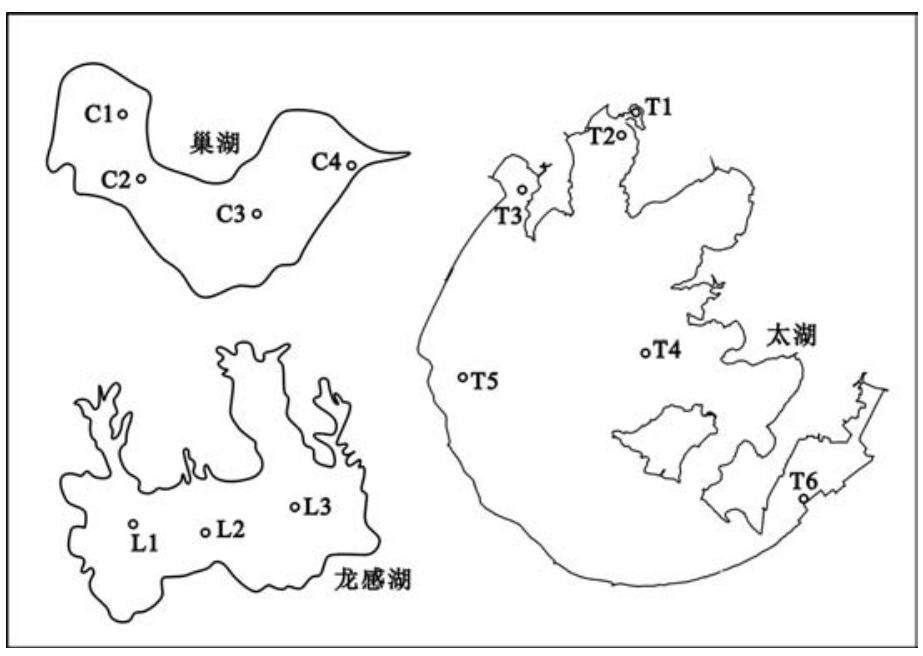

图 1 太湖、巢湖和龙感湖采样点示意图

Fig. 1 Sampling stations in Lake Taihu, Lake Chaohu and Lake Longgan 


\section{2 实验及方法}

在这些湖区进行的沉积物形态磷连续提取研究表明, 这些样点的总磷以及潜在的生物可利用磷 - 铁 锰结合态磷、铝结合态磷和有机磷存在着较大的空间差异. 而这些形态磷正是构成 BAP 的主要组分. 因此 可以据此认为沉积物中 BAP 含量空间变化 (垂直剖面和水平空间差异) 也较大. 采用铁氧化物试纸法难以 保证各样品的提取有均一的提取效率, 本研究采用经典的化学提取方法进行 BAP 的提取. 提取剂采用 $\mathrm{NaOH}(0.1 \mathrm{~mol} / \mathrm{L})-\mathrm{NaCl}(1.0 \mathrm{~mol} / \mathrm{L})$ 混合提取剂 ${ }^{[4]}$.

\section{1 条件实验}

以 $\mathrm{NaOH}-\mathrm{NaCl}$ 混合试剂为提取剂, 使用国标沉积物标样( 地矿部物测试所, 水系沉积物标准参考样 GSD - 9, 国家标准物质 GBW - 07309)进行条件实验, 确定提取实验方法, 利用同一沉积物样进行平行性分 析和组间方差分析, 比较提取效率和平行性, 确定最佳提取时间、取剂浓度等提取参数.

取 $0.1 \mathrm{~g}$ 国标沉积物样品, 加 $300 \mathrm{ml}$ 提取剂, 连续提取时间分别设定为 $1,2,4,6,8$ 和 $12 \mathrm{~h}$. 每个提取时 间分别平行提取 3 个样品, 并加试剂空白. 往复振荡频率为 $270 \mathrm{rpm}$, 提取完毕后在离心机中离心 $20 \mathrm{~min}$ ( $5000 \mathrm{rpm}, 3500 \mathrm{G}$ ), 取上清液 $10 \mathrm{ml}$, 加 $1 \mathrm{ml} 1.0 \mathrm{~mol} / \mathrm{L} \mathrm{HCl}$ 中和后, 用 $0.45 \mu \mathrm{m}$ 的混和纤维滤膜过滤, 磷钼 蓝比色法测定提取液中磷酸盐含量 ${ }^{[13]}$.

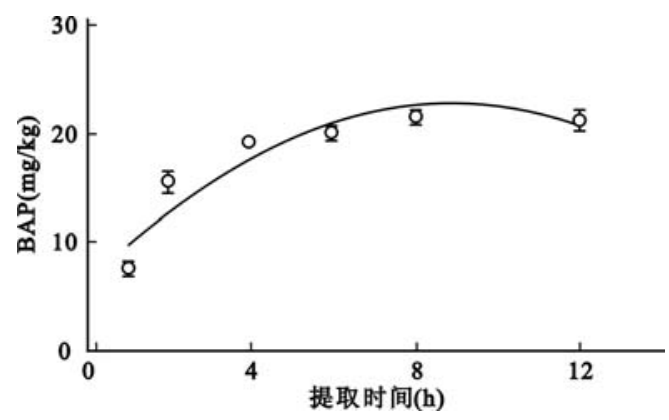

图 $2 \mathrm{NaOH}-\mathrm{NaCl}$ 提取效率时间曲线

从图 2 可以看出,利用标准沉积物样品进行条件 实验,平行样间平均误差都很小,数据可靠度较高. 从 曲线看,利用 $\mathrm{NaOH}-\mathrm{NaCl}$ 提取剂进行藻类可利用磷 的提取, 提取效率随振荡时间很快提高, 在达到 $8 \mathrm{~h}$ 后 提取趋于稳定. 与杨逸萍 ${ }^{[14]}$ 等在河口悬浮物及海洋 沉积物藻类可利用磷的研究中推荐的提取时间一致.

\section{2 实验方法}

在实验预研究中比较了相同提取方法和条件下, 不同预处理的结果, 发现提取得到的 BAP 为: 低温 $60^{\circ}$ C 烘干样 > 鲜沉积物样 > 自然风干样. 烘干可能导致 部分有机磷向生物可利用的无机磷转化导致 BAP 偏 高. 经样本量为 6 的方差分析, 鲜沉积物样和自然风 Fig. 2 Time curve of extraction effect with $\mathrm{NaOH}-\mathrm{NaCl}$ 干样无显著差异 ( 显著水平 $\alpha=0.01$ ). 由于风干样品更容易获得均一性, 因此风干样的 BAP 含量样品间标 准误差小于鲜样, 且风干样品更利于保存, 因此采用自然风干样品作为前处理方式.

样品经自然风干, 敲碎后, 各称取约 $0.1 \mathrm{~g}-0.15 \mathrm{~g}$, 加 $30 \mathrm{ml}$ 提取剂 $(0.1 \mathrm{~mol} / \mathrm{L} \mathrm{NaOH}+1 \mathrm{moL} / \mathrm{l} \mathrm{NaCl})$. 在 $50 \mathrm{ml}$ 的离心管中, 加塞密闭, 用往复式振荡器连续振荡提取 $8 \mathrm{hr}$. 振荡器振幅为 $5 \mathrm{~cm}$, 速度为 $270 \mathrm{rpm}$. 用提取剂作为试剂空白.

提取液经 $5000 \mathrm{rpm}(3500 \mathrm{G}$ )离心 $20 \mathrm{~min}$ 后, 倾出上清液, 经 $0.45 \mu \mathrm{m}$ 的混和纤维滤膜过滤后,量取 25 $\mathrm{ml}$ 过滤液. 加 $1 \mathrm{ml} 6 \mathrm{~mol} / \mathrm{L}$ 的 $\mathrm{HCl}$ 中和, 用磷钼蓝比色法比色测定得到磷酸盐含量 ${ }^{[13]}$. BAP 含量经含水率 换算成风干沉积物干重含量.

\section{3 结果和讨论}

\section{1 表层沉积物 BAP 的空间分布}

图 3 显示在 2002 年 10 月、2003 年 1 月及 2003 年 7 月三次采样得到的表层沉积物 BAP 含量结果. 图 中可以看出:太湖六个点中, 北太湖沉积物 BAP 含量大大高于南太湖及东太湖, 甚至有一个量级的差别. 其 中以梁溪河口 $\mathrm{T} 1$ 点和竺山湖 $\mathrm{T} 3$ 点最高, 这两个样点与太湖北部主要污染来源位置一致. $\mathrm{T} 1$ 点承接着来自 梁溪河的大量工业和生活污水, 而 T3 点较高的 BAP 值与该湖区西北部人湖的污染物有关. 随着太湖的主 要污染来源从北部向南部和东部输移, 逐渐沉积降解, 表层沉积物的 BAP 含量也随之下降. 北太湖 ( T1, $\mathrm{T} 2, \mathrm{~T} 3$ ) 表层沉积物的平均含量为 $259.5 \mathrm{mg} / \mathrm{kg}$, 而西部湖区 ( T5 )平均含量为 $114.6 \mathrm{mg} / \mathrm{kg}$, 湖心区 $(\mathrm{T} 4)$ 平均 
含量为 $40.6 \mathrm{mg} / \mathrm{kg}$, 而东太湖 $\mathrm{T} 6$ )平均含量为 $50.7 \mathrm{mg} / \mathrm{kg}$. 太湖湖心区 T4 沉积物的 BAP 在 6 个样点中含 量最低, 与该点远离污染源输人有很大的关系. 而东太湖 $\mathrm{T} 6$ 仅次于 $\mathrm{T} 5$ 点,理论上该点位于出湖口, 水体中 颗粒物和污染物的沉积降解路程最长, 但由于该湖区为养殖区, 渔业养殖带来的外源性污染也是该湖区 BAP 的一个来源. 由于 BAP 中重要的铁磷和有机磷组分与污染输人有很重要的相关关系, 污染物输人导 致的铁磷和有机磷的蓄积直接导致了沉积物中 BAP 含量的升高 ${ }^{[15]}$. 总的来说, 太湖沉积物 BAP 的分布呈 现为北部向东部和东南部降低的趋势, 直观地看, 该趋势与太湖水体的营养负荷分布特征关系一致. 总的 来说, 太湖沉积物中 BAP 的含量呈现北高南低,西高东低的梯度分布特点. 且这种分布特点与污染物的输 人特征密切相关.

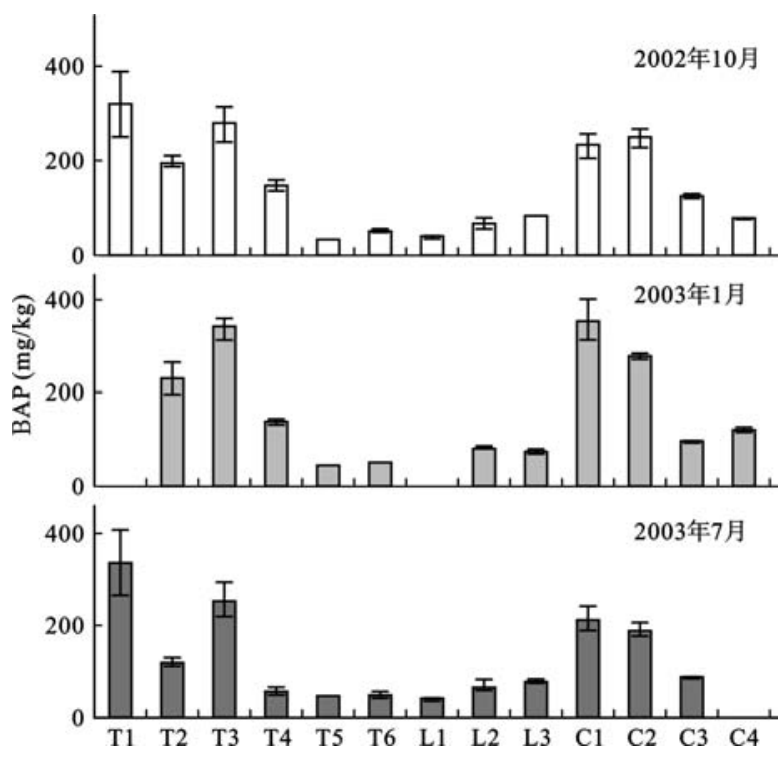

图 3 太湖、龙感湖和巢湖表层沉积物的 BAP

Fig. 3 BAP contents in surficial sediments of Lake Taihu, Lake Longgan and Lake Chaohu

龙感湖为草型湖泊, 主要人湖污染物来自农业和养殖业, 无重要的工业污染源. 全湖表层沉积物 BAP 含量很低, 且三个样点的 BAP 含量较为一致, 无显著差异, 其平均值为 $67.8 \mathrm{mg} / \mathrm{kg}$, 该湖泊沉积物的 BAP 含 量比太湖草型湖区 - 东太湖略高, 但显著低于污染较为严重的太湖北部湖区.

巢湖是一个富营养化湖泊,周边不仅有主要的工业污染废水排放,也有农业面源污染,其营养水平较 高, 其中 $\mathrm{C} 1$ 和 C2 点的 BAP 含量与北太湖相当, 与这两个点位于巢湖的主要人湖河流附近有很大关系, 这 两个点接受的工农业污染比 C3, C4 点要高的多, 其 BAP 空间分布表现出明显的西高东低的规律, 这与巢湖 西部为污染输人区, 向东逐渐稀释、沉降、降解的规律一致. 其西部湖区 $(\mathrm{C} 1, \mathrm{C} 2)$ 表层沉积物的 BAP 平均含 量为 $254.2 \mathrm{mg} / \mathrm{kg}$, 而东部湖区 ( C3, C4 B BAP 含量降低为 $101.9 \mathrm{mg} / \mathrm{kg}$.

\section{2 表层沉积物 BAP 的季节性变化}

从图 3 看出,三次采样的表层沉积物 $\mathrm{BAP}$ 含量的季节性变化并不显著,但从平均值看,夏秋冬三季( 分 别为 7 月, 10 月和 1 月 )太湖 6 个样点的平均值分别为 $143.6 \mathrm{mg} / \mathrm{kg}, 170.7 \mathrm{mg} / \mathrm{kg}$ 和 $161.5 \mathrm{mg} / \mathrm{kg}$, 表现为夏 季 BAP 含量低于秋冬季. 根据对太湖长期的监测表明, 太湖冬季由于水位较低, 人湖补水量较小, 污染较为 严重, 沉积物 BAP 含量应高于其他季节, 但是由于冬季的数据中 BAP 含量最高的 $\mathrm{T} 1$ 点数据缺失, 因此造成 冬季平均值偏低. 理论上说, 由于夏季微生物和藻类的生物活性最高, 对有机磷等生物可利用磷的分解作 用最强, 因此可以理解为夏季较低的 BAP 含量与生物分解作用有关 ${ }^{[16]}$.

\section{$3.3 \mathrm{BAP}$ 垂直分布规律}

各个湖区样点及不同季节( 夏秋冬三季), 沉积物 BAP 含量在深度变化上均表现为指数分布特征, 即 
BAP 含量随着深度的增加呈指数降低( 图 4 ), 说明随着沉积作用的增强, 沉积物中可利用磷逐渐向非生物 活性的磷形态转化. 同时, 沉积物间隙水中可溶性磷酸盐含量在一定的沉积深度内呈显著升高趋势, 并在 某个沉积深度上出现最大值, 呈峰型分布 ${ }^{[17]}$, 显示出 BAP 向可溶性磷酸盐转化能力增强. 因此, 在一定沉 积深度内, 沉积物 BAP 含量随深度的增加呈指数降低与 BAP 的沉积和生物地球化学转化过程共同控制有 关. 从历史沉积物看, 表层 BAP 含量较高的样点 BAP 历史沉积背景亦较高, 这可能和湖区的历史营养状况 有关. 从 BAP 的季节性垂直分布变化看, 其规律与表层沉积物的 BAP 的季节性变化规律一致.
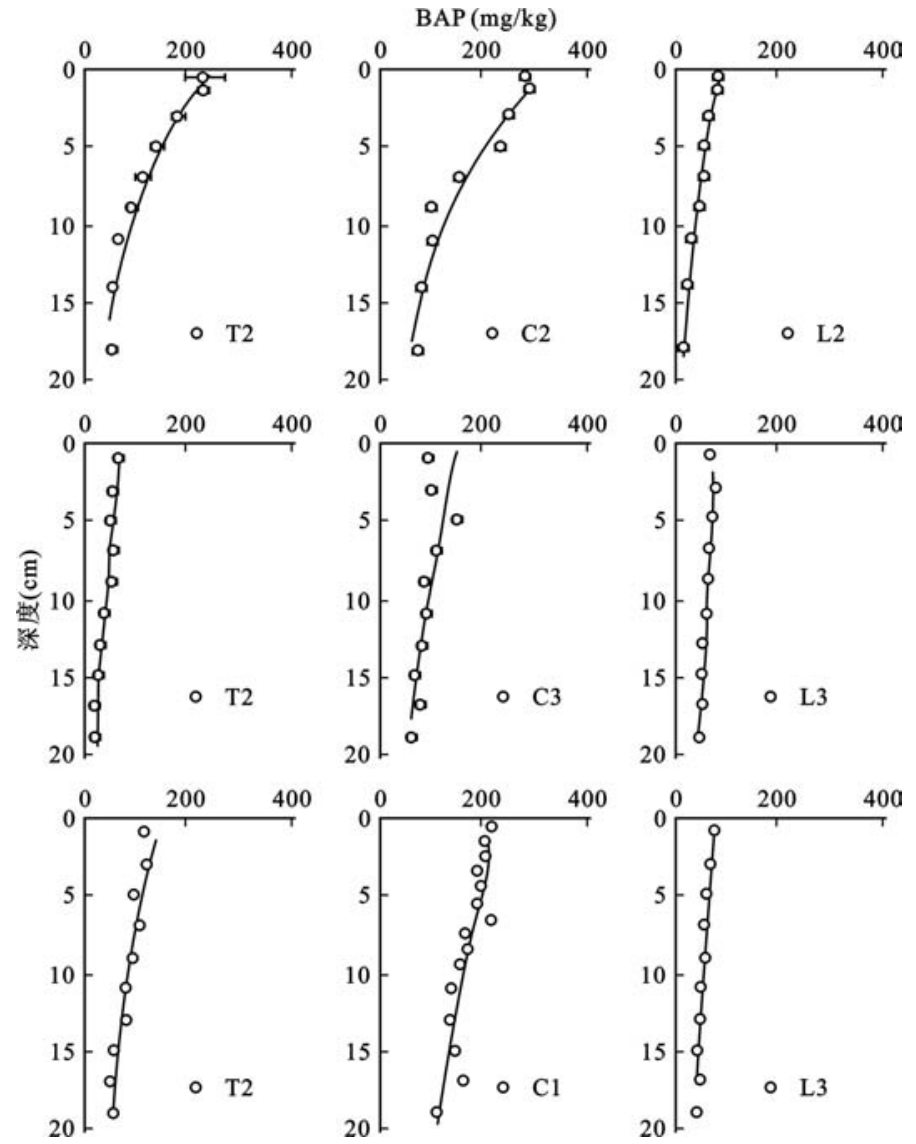

图 4 太湖、巢湖、龙感湖沉积物 BAP 垂向分布

Fig. 4 Vertical distribution of BAP in sediment of Lake Taihu, Lake Longgan and Lake Chaohu

\subsection{BAP 含量与水体营养状况关系}

BAP 含量表征着沉积物中潜在可供生物利用的活性磷含量, 由于 BAP 可通过化学和生物的作用转化 为活性磷进人水体, 并影响磷酸盐在水土界面间的释放速率 ${ }^{[18]}$. 因此, BAP 含量与水体中溶解性活性磷的 含量应存在着某种相关关系. 从太湖、巢湖和龙感湖的 BAP 含量与相应湖区水体溶解性活性磷的关系看, 他们存在着正相关关系( 图 5 ), 其相关方程为 $\operatorname{SRP}(\mathrm{mg} / \mathrm{L})=0.0001 \times \mathrm{BAP}(\mathrm{mg} / \mathrm{kg})+0.015\left(R^{2}=0.47\right)$. 但沉积物 BAP 含量较高的样点其含量与水体上覆水 SRP 相关性较 BAP 含量较低的样点相关性差, 图 5 显 示数据点距回归曲线离散较多, 即南太湖及龙感湖的沉积物 BAP 含量与水体磷负荷相关较好, 而巢湖及北 太湖的沉积物 BAP 含量相关稍差, 其可能的原因为更高的 BAP 在转化为 SRP 时转化效率差异性较大. 另 外, 虽然 BAP 较高造成湖区磷释放的潜力较高, 但湖水 SRP 浓度还与水体氧化还原条件、pH 和水体胶体物 质含量等环境因子有很大关系. 巢湖和北太湖均属于开敞性藻型湖泊/湖区,无大量水生植物生长, 水面复 
氧较草型湖区强烈 ${ }^{[17]}$, 水体氧化能力强于草型湖泊/湖区; 风浪导致的再悬浮作用在藻型湖区更为强烈, 释 放出来的磷酸盐进人上覆水后更容易被氧化和颗粒物吸附等生物地球化学作用也导致了沉积物 BAP 含量 和上覆水 SRP 含量相关性的降低. 从图 5 还能看出, 重污染湖区 ( 巢湖和北太湖) 和轻污染湖区 ( 龙感湖和 南太湖)的沉积物 BAP 含量表现为显著的差异分布特征, 同时相应湖区水体的磷负荷也表现为分异的 特征.

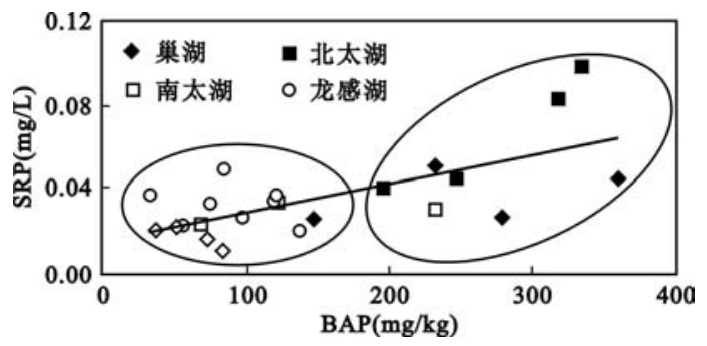

图 5 表层沉积物 BAP 含量与水体 SRP 关系

(南太湖指 $\mathrm{T} 4, \mathrm{~T} 5$ 和 $\mathrm{T} 6$ 点, 部分样点上覆水 SRP 含量数据缺失未包括在内 )

Fig. 5 Relationship between BAP in surficial sediments and SRP in overlying water

\section{4 结论}

北太湖、南太湖、巢湖和龙感湖沉积物 BAP 含量表现出显著的空间差异特性. 营养程度较高的北太湖 和巢湖相应的沉积物 BAP 也较高, 龙感湖和南太湖则较低. 由于夏季生物活性较高, 且湖区生物量也较高, 对磷的利用亦较高, 因此沉积物中 BAP 含量低于秋冬季. BAP 在沉积物中随深度呈指数降低, 显示 BAP 在 沉积作用下向非生物活性的磷形态转化. 沉积物 BAP 含量与水体磷负荷呈正相关关系,但污染程度较低的 湖区相关性好于污染程度较高的湖区.

\section{5 参考文献}

[ 1 ] Peters R H. Phosphorus availability in Lake Memphremagog and its tributaries. Limnol Oceanogr, 1981, 26 : $1150-1161$.

[ 2 ] Dorioz J M, Pelletier J P, Benoit P. Physico-chemical properties and bioavailability of particulate phosphorus of various origin in a watershed of Lake Geneva (France ). Water Research, 1998, 32( 2 ): 275 - 286.

[ 3 ] Reynolds C S, Davies P S, Sources and bioavailability of phosphorus fractions in freshwaters: a British perspective. Biological Reviews, 2001, 76( 1 ): $27-64$.

[ 4] Zhou Q X, Gibson C E, Zhu Y M. Evaluation of phosphours bioavailability in sediments of three contrasting lakes in China and the UK. Chemosphere, 2001, 42( 2 ): $221-225$.

[5] Ekholm P, Krogerus K. Determining algal-available phosphorus of differing origin: route phosphorus analyses versus algal assays. Hydrobiologia, 2003, 492( $1-3): 29-42$.

[6] Mortimer C H. The exchange of dissolved substances between mud and water in lakes. II. J Ecol, 1942, ( 30 ), $147-201$.

[ 7 ] Dorich R A, Nelson D W \& Sommers L E. Algal availability of sediment phosphorus in drainage waters of Black Creek Watershed. Journal of Environental Quality, 1980, 9( 4 ): 557 - 562.

[ 8 ] Miller W E, Greene J C \& Shiroyarna T. The Selenastrum capricornutum Printz algal assay bottle test and data interpretation protocol. U. S. EPA, Tech. Rep. EPA - 600/9-78-018. USEPA, Covallis, OR. 1978.

[9] Sharpley A N, Troegar W W, Smith S J. The measurement of Bioavailable Phosphorus in agricultural runoff. 
Journal of Environmental Quality, 1991, 20( 1 ): 235 - 138.

[ 10 ] Sharpley A N. An innovative approach to estimate bioavailable phosphorus in agricultural runoff using ironoxide impregnated paper. Journal of Environmental Quality, 1993, 22( 3 ): 597 - 601.

[11] Dils R M \& Heathwaite A L. Development of an iron oxide-impregnated paper strip technique for the determination of bioavailable phosphorus in runoff. Water Research, 1998, 32( 5 ): 1429 - 1436.

[12] 李文朝,尹澄清,陈开宁等. 关于湖泊沉积物磷释放及其测定方法的雉议. 湖泊科学, 1999, 11( 4$)$ : $296-303$.

[ 13 ] Murphy J \& Riley J P. A modified single solution method for the determination of phosphate in natural waters. Anal Chim Act, 1962, $27: 31-36$.

[14] 杨逸萍, 宋瑞星, 胡明辉. 河口悬浮物与海洋表层沉积物中藻类可利用颗粒磷的数量研究. 厦门大学 学报( 自然科学版), 1996, 35( 6 ): $928-935$.

[15] 张 路, 范成新, 池俏俏等. 太湖及其主要人湖河流沉积磷形态分布研究. 地球化学, 2004,33 ( 4 ): $423-432$.

[16] Sharpley A N, Robinson J S, Smith S J. Bioavailable phosphorus dynamics in agricultural soils and effects on water quality. Geoderma, 1995, (67):1 - 15 .

[17] 张 路, 范成新, 王建军等. 太湖草藻型湖区间隙水理化特性比较. 中国环境科学, 2004,24( 5 ): $556-560$.

[ 18 ] Mhamdi M A, Aleya L, Devaux J. Phosphorus exchanges between sediment and water in trophically different reservoirs. Water Research, 1994, 28( 9 ): 1971 - 1980. 